Artigo recebido em 19/03/2014

Aprovado em

$18 / 04 / 2014$

RAFAEL DUARTE

OLIVEIRA VENANCIO

Universidade Federal de

Uberlândia -

rdovenancio@gmail.com

Doutor em Meios e

Processos Audiovisuais pela Escola de

Comunicações e Artes

da Universidade de São

Paulo e Professor da

Graduação em Jornalismo

e da Pós-Graduação

em Tecnologias,

Comunicação e Educação da Universidade Federal de Uberlândia
Estudos em Jornalismo e Mídia

Vol. $11 \mathrm{~N}^{\circ} 1$

Janeiro a Junho de 2014

ISSNe 1984-6924

\section{Outros mundos do futebol: o exercício do isomorfismo linguístico na crônica esportiva}

\section{Rafael Duarte Oliveira Venancio}

\section{Resumo}

O presente artigo deseja observar como a crônica esportiva de futebol (especialmente a produção textual de Nelson Rodrigues e José Lins do Rego) consegue engendrar, em sua narrativa, mundos possíveis que, mesmo com atributos ficcionais, se vinculam à referencialidade dos fatos ocorridos no esporte. Utilizando-se o arcabouço teórico de Umberto Eco e de David Lewis, o objetivo aqui é refletir acerca desse exercício de isomorfismo linguístico, bem como desvelar as estratégias altermundistas utilizadas.

Palavras-chave

Futebol, Crônica Esportiva, Narrativa de Mundos Possíveis.

\begin{abstract}
This article wants to observe how football-themed sports chronicle (specially the textual production by Nelson Rodrigues and José Lins do Rego) can engender, in its narrative, possible worlds which, even with fictional attributes, are linked to the referentiality of the events in the sport. Using the theoretical framework of Umberto Eco and David Lewis, the goal here is to reflect on this exercise of linguistic isomorphism, as well as to unveil the other-world strategies used.
\end{abstract}

Keywords

Football (Soccer), Sports Chronicle, Possible Worlds Narrative. 


\section{Apito inicial}

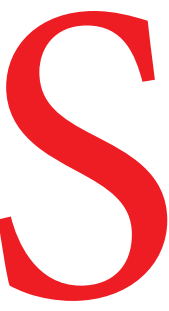

obrenatural de Almeida

desviando um gol certo. Didi como um "príncipe etíope de rancho". Negrinho do Pastoreio jogando futebol pelo Vasco para derrotar um time paulista depois do tempo normal mais prorrogação. Pessoas reais, situações maravilhosas. Pessoas maravilhosas, situações reais. Na crônica esportiva brasileira de futebol, seja nas páginas dos jornais ou compiladas em livro, o torcedor-leitor convive com a tradição de (re)inventar um jogo que está posto, (re)ler um jogo já visto, encontrar a poeticidade daquele esporte que é conhecido como "The Beautiful Game".

Tal como diz Nelson Rodrigues, um dos mestres pioneiros da crônica esportiva brasileira, a atividade do cronista não é idêntica a do jornalista tradicional. O papel dele não seria da análise fria e crua, mas sim algo mais próximo do lado mais literário da imprensa.

Ora, faltou, justamente à vitória gaúcha, o seu poeta. Os correspondentes brasileiros, que estavam no México, deviam mandar, de lá, telegramas rimados, ungidos de histerismo cívico. Mas como estamos em crise de Bilacs, o fabuloso triunfo só inspirou mesmo uma pífia correspondência, que nos enche de humilhação patriótica e vergonha profissional. Cada cronista da delegação, em vez de babar materialmente de gozo, mandou dizer ao seu jornal o seguinte: - "que os argentinos jogaram mais, que os argentinos mereceram vencer e que os brasileiros estavam apáticos".

Vejam vocês em que dá a mania da justiça e da objetividade! Um cronista apaixonado havia de retocar o fato, transfigurá-lo, dramatizá-lo. Daria à estúpida e chata realidade um sopro de fantasia (RODRIGUES, 1994, p. 11)
Nessa crônica de 31 de março de 1956, publicada na Manchete Esportiva acerca do título ganho pela Seleção Brasileira (representada pela Seleção Gaúcha) no Pan-Americano de Futebol de 1956, Nelson Rodrigues coloca as principais regras do estilo brasileiro de escrever crônicas de futebol: retocar "a estúpida e chata realidade" dando "um sopro de fantasia" ao transfigurá-la e dramatizá-la.

Assim, a crônica não ficaria nesse "mundo real" do futebol, mas sim promovendo "mundos" do esporte. O altermundismo era a regra e essa seria a maneira do bom jornalismo, afinal "o fato em si mesmo vale pouco ou nada. $\mathrm{O}$ que lhe dá autoridade é o acréscimo da imaginação" (RODRIGUES, 1994, p. 11).

Vemos assim que o altermundismo futebolístico das crônicas é um uso do isomorfismo linguístico, ou seja, a promoção de uma realidade similar a nossa, porém reajustada. Verificar quais são os mecanismos utilizados para tal tarefa é a proposta do presente artigo.

Com arcabouço teórico na Filosofia Analítica da Linguagem, com enfoque em David Lewis e Umberto Eco, a reflexão aqui se concentrará em um corpus formado por crônicas de Nelson Rodrigues e José Lins do Rego, pioneiros do gênero no Brasil. Tendo o conceito de "mundos possíveis" enquanto central, o trabalho fará uma breve reflexão teórica para depois proceder a descrição e as análises das estratégias promotoras do isomorfismo presente nas crônicas.

Eis aqui uma forma de entender como essa prática midiática do Jornalismo Esportivo, do lado de sua irmã literatura, faz construir suas "verdades". Tal como José Lins do Rego escreveu em sua estreia no Jornal dos Sports, 
Volto à crônica com o mesmo ânimo, com o mesmo flamenguismo, com a mesma franqueza. Nada de fingir neutralidade e nem de compor máscara de bom moço. Mas só direi a verdade. E este é um compromisso que estará acima do meu próprio coração de rubro-negro. Sou tão amigo de Platão como da verdade. Mas espero que o meu caro Platão esteja sempre com a verdade. (REGO, 2002, p. 27)

\section{Mundos Possíveis,}

\section{Linguagem e Produção de} Isomorfismo

Por definição, isomorfismo é homomorfismo bijetivo, ou seja, simplesmente a capacidade de duas estruturas terem os mesmos componentes, mas reorganizados de maneira diferente. Assim, mesmo diante de uma desordem, há correspondência entre todos os elementos, fazendo $\mathrm{x}$ e $\mathrm{y}$ serem idênticos e diferentes ao mesmo tempo, por exemplo.

No começo da Filosofia Analítca, tanto Russell como Wittgenstein trabalham com uma ideia de isomorfismo pautando a própria interação entre linguagem e mundo, entre proposições e fatos. Essa era a chave de compreensão do atomismo lógico, bem como fonte de seus paradoxos.

Ora, com o isomorfismo, você consegue pensar em situações lógicas no qual os mesmos elementos se tornam algo outro apenas por possuir uma estrutura distinta. Um exemplo "mais colorido" disso está no próprio filme Tron: o Legado (2011), de Joseph Kosinski, onde se brinca com essa ideia: em uma realidade feita pela interação entre linguagem artificial e o mundo virtual, há seres isomorfos que surgem tal como se fossem uma imperfeição do sistema. São idênticos aos outros programas (algoritmos) em composição, mas não em suas estruturas randômicas.

Isso força a lógica aceitar o campo das lógicas modais, quebrando o próprio paradigma da verdade da primeira Filosofia Analítica, onde o exercício da reflexão está na produção de modelos para entender a nossa produção de modelos de realidade, seja a nossa própria realidade, as realidades epistemológicas da ciência ou mesmo as realidades ficcionais, sendo que estas não podiam ser analisadas no escopo do atomismo lógico. Com isso, a observação da linguagem e o seu jogo interacional com o mundo para produzir "realidades" nos leva para uma definição de isomorfismo enquanto os mundos possíveis da linguagem. Dentro da Filosofia Analítica da Linguagem, o grande propositor dessa ideia é David Lewis com o seu realismo modal.

Realismo modal é "a tese que o mundo no qual fazemos parte é apenas um dentro de uma pluralidade de mundos e que nós que habitamos esse mundo somos apenas alguns dentre todos os habitantes

\section{A crônica não ficaria nesse "mundo real" do futebol, mas sim promovendo "mundos" do esporte}

de todos os mundos" (LEWIS, 2001, p. vii). Ou seja, a ideia de mundos possíveis não só existe, mas para Lewis, elas são entidades concretas separadas tanto de maneira causal como espaço-temporal do 
nosso mundo, sendo ele apenas um dos diversos mundos possíveis.

Assim, o realismo modal de David Lewis é uma das formas de encarar a possibilia. Uma das melhores aplicações da possibilia junto com a ideia de mundos possíveis, em um escopo geral, é a ideia de verossimilhança definida por Risto Hilpinen. Para ele, como bem define Lewis (2001, p. 24), "uma teoria é próxima da verdade quando o nosso mundo se assemelha a um mundo no qual essa teoria é a verdade exata. Uma teoria verdadeira é próxima da verdade porque o nosso mundo é um mundo onde essa teoria é verdade".

O mérito da proposta de Hilpinen é que ela distingue aspectos da verossimilhança cuja comparação através de perguntas [quizzes] que tendem a andar juntas. Uma teoria $\mathrm{T}$ define uma região no espaço de mundos possíveis: a saber, a classe de todos os T-mundos. A verdade completa define outra região: a unidade de classe do nosso mundo. Há três caminhos relevantes para comparar essas regiões em termos de distância de similaridade. (1) Tamanho: quão menor a região de T-mundos é, mais ela parece com a região pontual definida pela verdade. (2) Formato: quão mais compacta é a região de T-mundos é, menos ela consiste de partes soltas e espalhadas e mais ela parece com a região pontual definida pela verdade. (3) Separação: a distância, em uma abordagem próxima, entre a região dos T-mundos e nosso mundo. É a separação que mais claramente merece o nome "proximidade com a verdade". Mas tamanho pequeno e formato compacto também são métodos das teorias e também devem ser considerados aspectos da verossimilhança ou "veracidade" em um sentido amplo. Todos os três aspectos são envolvidos se nós considerarmos não só a separação na abordagem mais próxima, mas também outras questões de separação: quão distante estão os T-mundos do nosso mundo? (...). Verossimilhança, enquanto tal, é discutida na maioria das vezes em conexão com o progresso científico. Nós podemos creditar as falsas teorias dos tempos antigos com determinada gradação dentro da proximidade da verdade (LEWIS, 2001, p. 26).

No entanto, nesse amplo campo modal posto pela possibilia, David Lewis desconsidera totalmente a existência de mundos impossíveis. Para ele, os mundos possíveis são entidades concretas que articulam contrafactuais e uma boa dose de modificadores lógicos de restrição. Aliás, é com tais modificadores que Lewis rebate a ideia tanto de mundos impossíveis como a ideia de um isomorfismo linguístico:

Essa discussão dos modificadores de restrição me proporciona dizer o porquê eu não vejo uso para os mundos impossíveis, pareados com os mundos possíveis. Para comparação, vamos supor que viajantes nos contam de um lugar neste mundo - uma montanha maravilhosa, muito além do bosque onde as contradições são verdadeiras. Alegadamente, nós temos verdades da forma "Na montanha, tanto $\mathrm{P}$ como não-P". mas, se "na montanha" é um modificador de restrição, que trabalha limitando os domínios de quantificação explícita e implícita para certa parte de tudo que há lá, então ele não tem nenhum efeito nos conectivos funcionais-veritativos. Então a ordem do modificador e conectivos não fazem diferença. Então "Na montanha ambos P e Q" é equivalente a "Na montanha $\mathrm{P}$ e na montanha Q"; da mesma maneira "Na montanha não-P" é equivalente a "Não: na montanha P"; colocando esses juntos, a verdade alegada "Na montanha tanto $\mathrm{P}$ como não-P" é equivalente à contradição clara "Na 
montanha P e Não: na montanha P". Ou seja, não há diferença entre uma contradição dentro do escopo do modificador e uma contradição plena que tem o modificador nela”. Assim, eu dizer a verdade alegada acerca das coisas contraditórias maravilhosas que acontecem na montanha não é diferente de se contradizer. Mas não há ponto, apesar de maravilhoso, no fato onde você pode dizer a verdade através do ato de se contradizer. Assim, não há uma montanha onde as contradições são verdade (...). Se os mundos fossem tal como estórias ou contadores de estórias, haveria espaço para mundos para os quais as contradições seriam verdadeiras. A triste verdade sobre as prevaricações desses mundos não seria em si contraditórias. Mas mundos, da maneira a qual eu os entendo, não são tal como estórias ou contadores de estórias. Eles são como esse mundo; e esse mundo não é uma estória, nem mesmo uma estória verdadeira. Nem mundos devem ser substituídos por suas estórias (LEWIS, 2001, p. 7).

Só que para o presente trabalho, no limite, entendemos que estórias são as formas linguísticas de recortar o mundo para criar realidades, inclusive a própria que vivemos. Há o jeito que configuramos o mundo que vivemos com a nossa capacidade de linguagem, um jeito de configurar o mundo através da linguagem do Rádio, outro através da linguagem do Cinema, e assim por diante. Isso também é válido para a (re)presentação ficcional e os diversos mundos construídos igual ao nosso ou mesmo construídos a partir de outros (tal como as Infinitas Terras das histórias em quadrinhos da DC Comics). Afinal, como dissemos, a realidade mundana que percorremos é feita por suas (re)presentações e cada protocolo de linguagem possui a sua (re)presentação (ou sua maneira interativa dentro do ato (re)presentacional).
Além disso, tais estórias possuem gradações de similaridade, ou seja, Familienähnlichkeit, oarfamiliarteorizado por Ludwig Wittgenstein. Para esse arcabouço teórico, a Familienähnlichkeit é onde reside o mecanismo de definição, bem como a relação entre as diversas coisas relacionadas sob uma definição. $\mathrm{O}$ grande exemplo de Familienähnlichkeit é, para Wittgenstein, o próprio ar familiar que une todos os protocolos de linguagem tornando possível chamá-los de jogos de linguagem. Isso é retirado da noção de que sob a alcunha de jogos, há uma série de objetos que não possuem nada em relação, apenas a Familienähnlichkeit de jogo. Aliás, a própria semelhança familiar entre a linguagem e o jogo torna possível falar em jogo de linguagem, bastando lembrar das relações wittgensteinianas entre linguagem e xadrez.

Tal situação de Familienähnlichkeit é exatamente o resultado do isomorfismo linguístico. Aliás, é o isomorfismo linguístico que garante a interação e a atualização dos diversos protocolos de linguagens (i.e. jogos de linguagem) que compõem os diversos recortes de realidade que faz a relação linguagem-mundo e mesmo o desenvolvimento linguagemmundos promovida pela ficção. Assim, a nossa visão acerca da linguagem faz parte daquilo que David Lewis denomina (e critica) enquanto ersatzismo linguístico [linguistic ersatzism].

Ora, a palavra ersatz significa, em alemão, substituto. Normalmente, quando se diz que algo é ersatz é que ele é um substituto de baixa qualidade. Isso aconteceu porque, na Segunda Guerra Mundial, os ingleses que eram prisioneiros de guerra dos nazistas recebiam um "café substituto" [Ersatzkaffee] que era uma 
infusão que não utilizava pó de café, mas sim uma mistura de cereais tostados. Tal café substituto era considerado pior que o café "de verdade", com isso a palavra ersatz acabou ganhando sua conotação pejorativa.

David Lewis utiliza esse conceito para tratar aqueles que acreditam na hipótese de mundos possíveis, mas não acreditam na concretude de tais mundos. Com isso, o paraíso da possibilia ${ }^{1}$, seria apenas um paraíso barato [paradise on the cheap] porque aqueles que defendem o ersatzismo "dizem que, ao invés de uma incrível pluralidade de mundos concretos, nós temos apenas um mundo, e uma série incontável de entidades abstratas que representam maneiras que esse mundo poderia ter sido" (LEWIS, 2001, p. 136).

Tais mundos ersatz possuem o ato duplo de representar: “(1) Eles são representações, então de alguma maneira faz sentido dizer qual seria a situação segundo eles; e assim (2) eles são representativos, tomando o lugar daquilo que eles propõem representar" (LEWIS, 2001, p. 137). Tal caráter de representação pode ser dividido nos três tipos de ersatzismo que Lewis critica: o linguístico, o pictório e o mágico. Além disso, há um quarto tipo de ersatzismo, o não-descritvo, ou seja, onde não importa o caráter de representação.

Sobre o ersatzismo linguístico, que compõe o arcabouço teórico do presente trabalho, Lewis (2001, p. 141) afirma que nele "os mundos ersatz são como estórias ou teorias, construções de mundo a partir de alguma linguagem e representam em virtude de significados dados por especulação". Essa corrente seria a mais comum dentro da Filosofia Analítica da Linguagem, especialmente dentro do caminho traçado pelos influenciados por Leibniz e Wittgenstein, rivalizando apenas com o ersatzismo não-descritivo.

David Lewis (2001, p. 141) afirma que não conhece nenhum teórico que apoia explicitamente o ersatzismo pictório (onde os mundos ersatz seriam como imagens ou modelos em escala, representados por isomorfismo) ou o ersatzismo mágico (onde os mundos ersatz apenas representam, sendo simplesmente da natureza deles fazer isso e não há nada a dizer sobre isso). No entanto, para o caminho teórico posto por Lewis, tanto o ersatzismo pictório como o mágico são radicalizações do ersatzismo linguístico, especialmente se pensarmos nos termos de Gödel e do Tractatus, respectivamente.

Ora, o ersatzismo linguístico "constrói seus mundos ersatz enquanto conjuntos mais consistentes possíveis de sentenças" (LEWIS, 2001, p. 142). As formas de elaborar tais sentenças se dividem em três grupos básicos: (1) através da linguagem ordinária tal como defende Richard Jeffrey (1983). Aqui, esses mundos são feitos de estórias completas e consistentes narradas pela linguagem ordinária (por exemplo, a língua inglesa); (2) através de linguagem artificial ou protocolos de linguagem, como é o caso de toda a obra de Rudolf Carnap após A Sintaxe Lógica da Linguagem (CARNAP, 2001). Aqui há a construção de descrições de estado, equivalentes aos mundos possíveis de Leibniz e aos possíveis estados das coisas de Wittgenstein (CARNAP, 1947); e (3) através da elaboração de um conjunto atomista de fatos ao estilo do Tractatus, tal como faz Brian Skyrms (1981).

Nos três tipos, o que há de comum é a construção da operação simbólica que constrói a realidade a partir de uma 
determinada linguagem em interação com o mundo. Com isso, tais mundos são entidades formais (i.e. entidades lógicas) que possibilitam a identificação e o reconhecimento das diversas práticas linguísticas dentro do mundo ordinário.

É dentro dessa possibilidade que Umberto Eco (2008, p. 103) nos questiona se "é possível falar de mundos possíveis". Para ele, a construção de mundos possíveis é chave para a compreensão da constituição do texto enquanto obra aberta, bem como o papel da sua interação e interpretação, através daquilo que ele denomina de Leitor-Modelo.

Ora, no Leitor-Modelo reside a propriedade do texto prever o leitor. Leitor esse capaz de cooperar em sua movimentação interpretativa tal qual o autor pensou no momento da concepção do texto. "Podemos dizer melhor que o texto é um produto cujo destino interpretativo deve fazer parte do próprio mecanismo gerativo" (ECO, 2008, p. 39).

Dessa forma, podemos utilizar a metáfora de que gerar um texto é executar uma xadrezística. Tal como Eco (2008, p. 39) alude, na estratégia de jogo, o estrategista projeta um modelo de adversário: "se efetuo este movimento - aventurava Napoleão - Wellington deveria reagir assim. Se executo este movimento - argumentava Wellington -, Napoleão deveria reagir assim".

Em Waterloo, "Wellington construiu um Napoleão-Modelo que se parecia ao Napoleão concreto mais do que o Wellington-Modelo, imaginado por Napoleão, se parecia ao Wellington concreto" (ECO, 2008, p. 39). Algo similar ocorre nas práticas textuais e, consequentemente, nas práticas midiáticas. Além disso, "o bravo estrategista deve levar em consideração também estes eventos casuais, com um cálculo probabilístico próprio. É como deve agir o autor de um texto" (ECO, 2008, p. 39). É interessante notar esse movimento que, "por um lado, o autor pressupõe, mas, por outro, institui a competência do próprio Leitor-Modelo" (ECO, 2008, p. 40).

Umberto Eco (2008, p. 40) deixa claro que "prever o próprio Leitor-Modelo não significa somente 'esperar' que exista, mas significa também mover o texto de modo a construí-lo. O texto não apenas repousa numa competência, mas contribui para produzi-la”. Assim, há a expectativa de que as coerções pragmáticas do modelo de decodificação (ECO, 2008, p. 38) não aconteçam pela própria instituição do Leitor-Modelo como target, através de "perspicácia sociológica e com brilhante mediedade estatística" (ECO, 2008, p. 41).

Assim, seja no USA Today, no Agora ou no livro Finnegans Wake, os autores buscam construir o seu Leitor-Modelo da forma mais precisa possível, mesmo que seja impossível. Ora, o livro de James Joyce "constrói o próprio Leitor-Modelo, escolhendo os graus de dificuldade linguística, a riqueza das referências e inserindo no texto chaves, alusões, possibilidades mesmo que variáveis de leituras cruzadas" (ECO, 2008, p. 43).

São essas chaves, alusões e possibilidades que constituem a base dos mundos construídos por essas obras, conseguindo até mesmo incluir a ficcionalização e o altermundismo que encontramos nas crônicas de futebol aqui analisadas. Além disso, Eco (2008, p. 110) define que tais mundos possíveis são construtos culturais.

Assim, para a construção de um 
determinado mundo através de um texto, há a necessidade de fazer referência aos dados à mão daquilo que se imagina ser seu leitor, o seu Leitor-Modelo. Aliás, a primeira questão que deve estar à mão para construir os mundos possíveis é a própria realidade do nosso mundo "real":

No quadro de uma abordagem construtivista dos mundos possíveis, também o chamado mundo "real" de referência deve ser entendido como um construto cultural. Quando no Chapeuzinho Vermelho, julgamos "irreal" a propriedade de sobreviver ao ingurgitamento feito por um lobo, é porque, mesmo em medida intuitiva, compreendemos que esta propriedade contradiz o segundo princípio da termodinâmica. Mas o segundo princípio da termodinâmica constitui precisamente um dado da nossa enciclopédia. Basta mudar de enciclopédia e passaria a valer um dado diferente. $\mathrm{O}$ leitor antigo que lia que Jonas foi devorado por um peixe e ficou três dias no seu ventre, para depois sair intacto, não achava que esse fato estivesse em desacordo com a sua enciclopédia. São extrassemióticas as razões que julgamos a nossa enciclopédia melhor do que a sua (por exemplo, consideramos que, adotando a nossa, conseguiremos prolongar a vida média e construir centrais nucleares), mas é certo que para o leitor antigo a história do Chapeuzinho Vermelho teria sido verossímil, por estar em consonância com as leis do mundo "real" (ECO, 2008, p. 112).

Com isso, seguindo a metodologia de Eco, temos um $\mathrm{W}_{0}$, que é a nossa realidade "enciclopédica" (como vemos o nosso mundo "real", Umberto Eco o chama de "mundo de referimento), um $\mathrm{W}_{\mathrm{N}}$, que é o mundo construído pela narrativa de uma obra focado nas expectativas de um Leitor-Modelo ("mundo narrativo" para Umberto Eco) e um $W_{R}$, que é como o leitor empírico prevê que seja o $\mathrm{W}_{\mathrm{N}}$.
Além disso, para cada personagem $\mathrm{C}$, há como ele vê o $\mathrm{W}_{\mathrm{N}}$, denominado $\mathrm{W}_{\mathrm{NC}}$. Bem como, o leitor empírico pode prever como é que um dado personagem $\mathrm{C}$ vê o $\mathrm{W}_{\mathrm{N}}$, montando assim um $\mathrm{W}_{\mathrm{RC}}$. E esse mesmo leitor pode prever como determinado personagem imagina como outro personagem vê o $\mathrm{W}_{\mathrm{N}}$ configurando um $\mathrm{W}_{\text {RCC }}$.

$\mathrm{O} \mathrm{W}_{\mathrm{N}}$ é composto por um conjunto sequencial de estados de coisas (que vai do primeiro estado $s_{1}$ até $s_{n}$ ) e uma ordenação por intervalos temporais (que vai de $t_{1}$ até $\left.t_{n}\right)$. O mesmo se aplica para os demais mundos, sendo que os estados de coisas e a ordenação temporais são isomórficas entre os mundos.

Por fim, há de se notar que "o texto em seu conjunto não é um mundo possível: trata-se de uma parcela de mundo real", afinal, ele é fruto de seu $W_{0}$, "e é no máximo uma máquina para produzir mundos possíveis", ou seja, o da fábula $\left(\mathrm{W}_{\mathrm{N}}\right)$, os das personagens da fábula $\left(\mathrm{W}_{\mathrm{NC}}\right)$ e os das previsões do leitor empírico $\left(\mathrm{W}_{\mathrm{R}}\right.$, $\left.\mathrm{W}_{\mathrm{RC}}, \mathrm{W}_{\mathrm{RCC}}\right)(\mathrm{ECO}, 2008$, p. 149).

Assim, para entender o funcionamento narrativo da crônica esportiva de futebol em sua promoção de ficcionalização e altermundismo, precisamos demarcar tais mundos possíveis e vislumbrá-los em esquemas narrativos. Essa é a tarefa de análise da nossa próxima seção.

\section{Em quais mundos o futebol está?: Analítica das Crônicas Esportivas}

No presente corpus, temos dois períodos temporais de crônicas bem determinados: (1) uma época de préconsolidação do futebol brasileiro, antes de sua primeira conquista máxima (a Copa de 1958), composto de crônicas 
de José Lins do Rego entre 1945 e 1957; e (2) um longo período de auge, com o tricampeonato mundial de 1958-19621970, encerrado por um sentimento de decadência com as Copas de 1966-19741978 nas crônicas de Nelson Rodrigues entre 1955 e 1978.

\section{José Lins do Rego: \\ $W_{0}$ do futebol $+W_{0}$ da literatura $=W_{N}$ da crônica}

O José Lins do Rego romancista está todo aqui, nas suas crônicas apaixonadas sobre futebol. Com toda a sua força de "eterno menino de engenho", para repetir o que dele dizia Otto Maria Carpeaux. Com toda a coragem meio destrambelhada do capitão Vitorino Carneiro da Cunha, de Fogo Morto, alucinado com a provocação dos moleques que o chamavam de "Papa-Rabo", a correr atrás deles sacudindo o rebenque. Com toda a sua generosidade de homem da terra, até porque, homem culto, carregado de literatura inglesa na sua formação, era muito mais um homem da terra do que dos livros, era brasileiríssimo por seu amor à terra. Ser "mais um homem da terra do que dos livros" era frase dele mesmo, quando queria elogiar alguém - é Carpeaux ainda que lembra (CASTRO apud REGO, 2002, p. 19).

"Um homem da terra". A lembrança que Marcos de Castro, compilador das crônicas de José Lins do Rego, nos remete à caracterização do cronista feita por Otto Maria Carpeaux é algo decisiva no seu estilo de retratar um "outro" futebol. Com crônicas curtas, normalmente se concentrando em pequenos fatos dos jogos de futebol do que em partidas inteiras, Rego costumava emparelhar jogos de futebol a fatos da cultura nacional em sua proposta altermundista.

Um dos exemplos disso está em uma crônica de 1945, intitulada "O bravo

Biguá":

Todo o estádio viu-o cair fulminado, como se uma bala o tivesse atingido no coração.

Todos os rubro-negros sentiram aquela dor imensa que prostrava o seu maior herói, naquela tarde de sombra e neblina.

Era o índio Biguá vítima de uma cilada do destino cruel. Vi a sua dor na fúria com que se encheu para redimir com um gol aquele outro com que derrotara sua equipe.

Vi-o de cabeça baixa no vestiário, e lhe teria dito, com toda a minha paixão de Flamengo traído pela chance: "Nada de cabeça baixa, índio bravo, se há no Flamengo quem possa andar de cabeça levantada és tu, esteio de nossas vitórias."

Depois vi-o nos braços do povo, carregado pelos fãs, a correr lágimas dos seus olhos. Então me lembrei das palavras do pajé de Gonçalves Dias ao filho:

"Não chores meu filho

Não chores que a vida

É luta renhida

Viver é lutar.

A vida é combate

Que aos fracos abate

Que aos bravos e aos fortes

Só pode exaltar.”

Índio Biguá, de tuas pernas de bronze e de tua coragem de leão muito espera o Flamengo, que não se entrega nunca (REGO, 2002, p. 43-44).

Ora, Biguá, apelido de Moacir Cordeiro, foi um lateral-direito (em tempos do esquema tático WM, a posição se chamava alfo direito) do Flamengo dos anos 1940 conhecido mais pela sua garra do que por sua técnica. Nascido no Paraná, não se sabe direito das suas origens, mas sua representação fotográfica parece indicar que ele poderia ser descendente de índios.

No dia 16 de setembro de 1945, um 
domingo, na rodada final do primeiro turno, o Flamengo, campeão de 1944, foi a São Januário pegar o favorito Vasco, que estava invicto. Além disso, no jogo de ida, o Flamengo tinha sofrido uma vexatória goleada para a equipe cruz-maltina: 5 a 1 (13 de maio de 1945). No entanto, uma crise pesava no Vasco: nove anos sem um título carioca.

A "fila", segundo a lenda, residiria no fato de que o último título do Vasco, em 1936, em cima do Andaraí irritara o macumbeiro do adversário, conhecido por Arubinha. Jurando vingança, Arubinha teria enterrado um sapo no gramado de São Januário para que a equipe vascaína jamais fosse campeã outra vez.

Ofato/lenda fora lembrado por JoséLins do Rego em crônica anterior ao jogo, de 14 de setembro de 1945, provocadamente intitulada "O sapo do Arubinha" e que terminava com o cronista afirmando que acreditava nos poderes do sapo.

No papel, o Flamengo do técnico Flávio Costa - composto por Luis Borracha, Newton e Norival; Biguá, Bria e Jaime;
Adilson, Zizinho, Pirilo, Perácio e Jarbas - era superior ao Vasco invicto de Ondino Vieira escalado com Rodrigues, Augusto e Rafanelli; Berascochea, Ely e Argemiro; Djalma, Lelé, Isaías, Ademir e Chico. No entanto, logo aos 10 minutos de jogo, o uruguaio Berascochea abriu o placar para o Vasco.

O Flamengo lutou pelo seu caminho no jogo e, aos 24 minutos do segundo tempo, Zizinho consegue o empate.

Parecia que o Flamengo conseguiria lavar a sua honra quando, faltando oito minutos para o fim do jogo, Biguá faz o gol contra que daria a vitória ao Vasco. Eis o $\mathrm{W}_{0}$ da crônica de José Lins do Rego. Com isso, analisando a crônica encontramos a seguinte construção de mundos possíveis, tendo Biguá como personagem C (ver tabela 1):

José Lins do Rego constrói uma narrativa onde Biguá não é um vilão da derrota do Flamengo, mas sim um herói vencido, tal como o personagem principal da "Canção do Tamoio" citada na crônica.

TABELA 1

Mundos Possíveis de "O bravo Biguá"

\begin{tabular}{|c|c|c|c|c|c|}
\hline \multirow[t]{2}{*}{$\mathbf{W}_{0}$} & \multirow{2}{*}{$\begin{array}{c}\square \text { Vasco } 2 \times 1 \text { Flamengo } \\
\text { (16/09/1945) } \\
\square \text { Poema de Gonçalves Dias } \\
\square \text { Características físicas e } \\
\text { táticas de Biguá (olhos } \\
\text { puxados, garra no campo) }\end{array}$} & $\mathbf{W}_{\mathrm{N}}$ & $\begin{array}{c}\square \text { "Uma cilada do } \\
\text { destino cruel" } \\
\square \text { Conselho do Pajé } \\
\text { ao filho ferido } \\
\square \text { Índio Biguá }\end{array}$ & $\mathbf{W}_{\mathrm{R}}$ & $\begin{array}{c}\square \text { Uma partida injusta } \\
\square \text { Futebol lírico } \\
\square \text { Tom “da terra” }\end{array}$ \\
\hline & & $\mathbf{W}_{\mathrm{NC}}$ & $\begin{array}{c}\square \text { “dor imensa" } \\
\square \text { "traído pela } \\
\text { chance" }\end{array}$ & $\mathbf{W}_{\mathrm{RC}}$ & $\begin{array}{c}\square \text { Um herói ferido } \\
\square \text { Alguém que vai se } \\
\text { superar }\end{array}$ \\
\hline
\end{tabular}

Fonte: Elaboração do Autor 
Aproveitando que o jogador tinha características físicas - e um discreto apelido - de Índio, Rego faz o emparelhamento da enciclopédia do futebol com a enciclopédia da literatura brasileira no $\mathrm{W}_{0}$ promovendo isomorfismo no $\mathrm{W}_{\mathrm{N}}$ e, com isso, um leitor que estivesse zangado com Biguá no $\mathrm{W}_{0}$ encontraria um leitor-modelo em $\mathrm{W}_{\mathrm{R}}$ que reconhece os esforços do jogador flamenguista.

Da mesma forma que une enciclopédia do futebol com enciclopédia da literatura para criar heróis da crônica, José Lins do Rego cria seus vilões. Um exemplo clássico foi o correspondente inglês que acompanhou o Arsenal em seu tour pelo Brasil, onde disputou amistoso contra o Flamengo em 29 de maio de 1949 e perdeu vexatoriamente por 3 a 1 . Curta e intitulada "Um inglês de Dickens", a crônica falava:

O mestre Dickens criou, em seus admiráveis romances, figuras de imbecis que ficaram na galeria do romance universal. Os imbecis de Dickens são eternos. E continuam a viver na terra que tem dado os maiores gênios do mundo.

$\mathrm{Ai}$ está esse jornalista que acompanhou o Arsenal como um autêntico espécimen da família numerosa dos imbecis de plantão. Para um jornal de milhões de leitores mandou dizer que a derrota do Arsenal pelo Flamengo não foi uma derrota de iguais para iguais, mas de sportmen contra anti-esportivos.

E que, após o jogo, os brasileiros ficaram tão loucos que atearam fogo às arquibancadas (REGO, 2002, p. 111).

Com isso, analisando a crônica encontramos a seguinte construção de mundos possíveis, tendo o jornalista inglês como personagem $\mathrm{C}$ (ver tabela 2 ):

José Lins do Rego, com suas crônicas, mostra esse princípio de consolidação do gênero na tribuna brasileira. Após ter Lima Barreto criticado o esporte na imprensa como sendo não-brasileiro, o cronista, bem ao seu estilo como autor literário, equipara o esporte com a literatura brasileira com suas crônicas, promovendo $\mathrm{W}_{\mathrm{N}}$ semelhantes àqueles que encontramos nos livros clássicos do país.

TABELA 2

Mundos Possíveis de "Um inglês de Dickens"

\begin{tabular}{|c|c|c|c|c|c|}
\hline \multirow[b]{2}{*}{$\mathbf{W}_{0}$} & \multirow{2}{*}{$\begin{array}{c}\square \text { Flamengo } 3 \times 1 \text { Arsenal } \\
\text { (29/05/1949) } \\
\square \text { Obra de Charles Dickens } \\
\square \text { Notícia do jornalista inglês } \\
\text { no jornal do seu país } \\
\text { (The Times?) }\end{array}$} & $\mathbf{W}_{\mathrm{N}}$ & $\begin{array}{c}\square \text { Tradição imbecil } \\
\text { da Inglaterra } \\
\square \text { Mesquinharia } \\
\text { colonialista }\end{array}$ & $\mathbf{W}_{\mathrm{R}}$ & $\begin{array}{c}\square \text { Injustiça contra o } \\
\text { Brasil } \\
\square \text { Futebol decadente da } \\
\text { Inglaterra em equipe } \\
\text { e em imprensa } \\
\square \text { Exaltação "da terra" }\end{array}$ \\
\hline & & $\mathbf{W}_{\mathrm{NC}}$ & $\begin{array}{c}\square \text { Não considera } \\
\text { brasileiros iguais a } \\
\text { ingleses } \\
\text { Brasileiros como } \\
\text { antidesportistas e } \\
\text { selvagens }\end{array}$ & $\mathbf{W}_{\mathrm{RC}}$ & $\begin{array}{c}\square \text { Um vilão sem } \\
\text { escrúpulos } \\
\square \text { Um imbecil }\end{array}$ \\
\hline
\end{tabular}

Fonte: Elaboração do Autor 


\section{Nelson Rodrigues: $\mathrm{W}_{\mathrm{NC}}$ dos arquétipos}

Se José Lins do Rego utilizava analogias com a literatura para criar outros mundos do futebol, baseado em isomorfismo no $\mathrm{W}_{\mathrm{N}}$, com seus heróis patrióticos e vilões intrusos, Nelson Rodrigues utilizava qualquer referência cultural para construir grandes $\mathrm{W}_{\mathrm{NC}}$ para seus personagens retratados.

Os personagens poderiam ser reais, membros do $\mathrm{W}_{0}$, ou intrusos a ele, pertencentes apenas ao $\mathrm{W}_{\mathrm{N}}$, ao mundo narrativo da crônica. Com isso, seus personagens do futebol se tornavam arquétipos, tal como Nelson Rodrigues fazia com seus textos literários e teatrais.

Um bom exemplo de crônica com personagem real está no texto "Beau Yustrich Geste", onde o técnico Yustrich, treinador do Atlético Mineiro, que vestiu a camisa do Brasil em amistoso contra a Iugoslávia em 19/12/1968, é comparado ao capitão do livro e filme Beau Geste. Em um texto longo, característico das crônicas de Rodrigues, Nelson primeiro nos explica o que deseja recortar de Beau Geste:

Houve um momento em que só restaram dois sobreviventes: - o capitão e o leitor. Com a guarnição exterminada, que fariam um mísero capitão e o simples leitor? O leitor, como se sabe, é um inimigo pessoal do risco. E o capitão teria que suportar sozinho os azares da guerra. Entregar-se era impossível ou, por outra, inútil. Os árabes o matariam até o último vestígio.

$\mathrm{E}$ eis que de repente ocorre ao capitão uma ideia genial. Ele vai apanhando os defuntos um por um, e os distribui pelas seteiras. Em seguida, sai atirando por detrás de cada morto. Ao longe, os sitiantes têm a sensação de que a guarnição continua intacta (...). Os bandidos pensavam: - "Não é possível! Não é possível!". Mas as balas continuavam a chover sobre eles. E por fim, tomados de um pavor fatal, saíram correndo e, segundo consta, estão correndo até hoje. Eis o que eu queria dizer: - o bom comandante é autor dos mais cínicos e deslavados milagres (RODRIGUES, 1993, p. 139-140).

Posta a referência cultural, Nelson Rodrigues a usa para analisar Yustrich:

Contei a história acima pensando na vitória de anteontem, no Estádio Magalhães Pinto. Os mineiros venceram em condições admiráveis. Começaram perdendo por $2 \times 0$. Quando se temia uma goleada, eis que o Atlético passou a uma reação maravilhosa. Sua equipe parecia morta e enterrada para o triunfo. E súbito, com os brios mais eriçados do que as cerdas bravas do javali, seus homens despertaram da falsa morte. Foi um espetáculo empolgante de paixão.

Mas eu pergunto: - quem foi, acima de todos e de tudo, o autor do milagre? Eis o seu nome: - Yustrich. Temos a mania de dizer que técnico não ganha jogo. Bem sei que ele não dá uma única e escassa botinada. $\mathrm{E}$ nem enfia os gols da vitória. Mas, sem aparecer, ele pode estar por trás de cada botinada, dispondo. $\mathrm{E}$ o nosso Yustrich é do tipo guerreiro do capitão do Beau Geste.

No romance, o militar punha os defuntos para dar tiros em todas as direções, como um Tom Mix. E Yustrich segue a mesma linha. Para ele, uma partida, e sobretudo internacional, é uma guerra. Nenhum dos jogadores fica no meio de campo bocejando ou de braços cruzados. Todos lutam e todos defendem: um por um e todos por todos. Aí está o milagre de Yustrich. Os times que dirige adquirem, antes de mais nada, a sede e a fome de vitória (RODRIGUES, 1993, p. 140).

Com isso, analisando a crônica 
encontramos a seguinte construção de mundos possíveis, tendo o capitão como personagem C1 e Yustrich como

personagem C2 (ver tabela 3):

TABELA 3

Mundos Possíveis de "Beau Yustrich Geste”

\begin{tabular}{|c|c|c|c|c|c|}
\hline \multirow{3}{*}{$\mathbf{W}_{0}$} & \multirow{3}{*}{$\begin{array}{c}\square \text { Brasil (Atlético Mineiro) } 3 \times 2 \\
\text { Iugoslávia (19/12/1968) } \\
\square \text { Beau Geste } \\
\square \text { Atuação de Yustrich como } \\
\text { treinador }\end{array}$} & $\mathbf{W}_{\mathrm{N}}$ & $\begin{array}{l}\square \text { Brasil (Atlético } \\
\text { Mineiro) } 3 \text { x } \\
2 \text { Iugoslávia } \\
\text { (19/12/1968) } \\
\square \text { Beau Geste }\end{array}$ & $\mathbf{W}_{\mathrm{R}}$ & $\begin{array}{c}\square \text { Jogo é semelhante ao } \\
\text { Livro/Filme }\end{array}$ \\
\hline & & $\mathbf{W}_{\mathrm{NC} 1}$ & $\begin{array}{c}\square \text { Determinado contra o } \\
\text { sítio árabe } \\
\square \text { Usa dos defuntos para } \\
\text { criar ilusão de ação, } \\
\text { produzindo força e } \\
\text { garra }\end{array}$ & $\mathrm{W}_{\mathrm{RC} 1}$ & $\begin{array}{c}\square \text { Um Herói tal como Tom } \\
\text { Mix } \\
\square \text { “cínico e deslavado" }\end{array}$ \\
\hline & & $\mathbf{W}_{\mathrm{NC} 2}$ & $\begin{array}{c}\square \text { Determinado contra os } \\
\text { iugoslavos } \\
\square \text { Usa a derrota para } \\
\text { criar ilusão de ação, } \\
\text { produzindo força e } \\
\text { garra }\end{array}$ & $\mathbf{W}_{\mathrm{RC} 2}$ & $\begin{array}{l}\square \text { Um herói tal como o } \\
\text { capitão do Beau Geste } \\
\square \text { "cínico e deslavado" }\end{array}$ \\
\hline
\end{tabular}

Fonte: Elaboração do Autor

Construindo um $\mathrm{W}_{\mathrm{N}}$ extremamente referencial, mas comparando os personagens em seus arquétipos narrativos na construção de mundo deles $\left(\mathrm{W}_{\mathrm{NC1}}\right.$ e $\left.\mathrm{W}_{\mathrm{NC} 2}\right)$, Nelson Rodrigues consegue o emparelhamento das enciclopédias contidas no $\mathrm{W}_{0}$ no mundo construído pelo leitor-modelo. Assim, um jogo se torna analisável a partir de um livro, um personagem real a partir de um arquétipo da ficção.

O mesmo acontecia para seus personagens fictícios. Sobrenatural de Almeida, o inimigo de todos os clubes e do Fluminense, e Gravatinha, o torcedorsímbolo do Tricolor das Laranjeiras eram compostos por referências culturais para se inserir arquetipicamente no jogo de futebol. E essas referências não precisavam ser coesas:

Vocês conhecem sua tenebrosa história. A grande fase do Sobrenatural de Almeida ocorreu na Idade Média. Era ele, na época, a figura mais adulada, mais promovida. Todos os dias, seu nome saía na coluna do Ibrahim. Quantas vezes não apareceu, em página dupla, na Manchete? Enquanto os outros andavam de bonde e, inclusive, de taioba, o miserável usava um big automóvel (Diga-se que seu carro tinha cascata artificial, com filhote de jacaré.) Nos dias quentes, um escravo núbio o abanava com a Revista do Rádio.

Com o fim da Idade Média, começou a decadência do Sobrenatural de Almeida. O primeiro a se despedir, exigindo pesada indenização trabalhista, foi o mordomo de casaca, que era uma das atrações turísticas do seu palácio. $\mathrm{Na}$ Renascença, o Sobrenatural ficou reduzido ao salário mínimo. E assim veio rolando, de humilhação em humilhação. Certa vez, cruzou com dom Hélder, na esquina de Sete com Avenida. Correu para o ilustre arcebispo de mão estendida. Eis a resposta do nosso Hélder: "Não tenho trocado". Era a suprema desfeita.

Hoje, o Sobrenatural mora num quarto infecto, em Irajá. E pior: - 
todas as manhãs, ao acordar, tem de entrar na fila do banheiro coletivo. Daí o seu horror aos homens e aos clubes. Seu campo de ação está limitado ao futebol. Podia gostar de um clube. Não. Quer ver a caveira de todos (RODRIGUES, 1994, p. 138139).

$$
\text { Nessas crônicas arquetípicas, }
$$
Nelson Rodrigues inaugura uma tradição de personagens para a crônica futebolística brasileira, todas baseadas no altermundismo. Um exemplo disso está na criação do Lance!, diário esportivo que contou com cronistas fictícios, cada um torcedor de um time. Era a vez do personagem escrever e ser escrito em seu mundo narrativo.

A partir de Nelson Rodrigues, podemos entender cronistas mais novos como José Roberto Torero e sua ampla gama de personagens ficcionais (TORERO \& PIMENTA, 2002), bem como os cronistas de "outro mundo" do Lance! tais como: Nilton Severiano (Botafogo), Tião Fiel (Corinthians), Scarlet Breu (Flamengo), Vitral de Almeida (Fluminense), Massimo Divino (Palmeiras), Doca e Doquinha Gonzaga (Santos), PH Bueno de Toledo (São Paulo) e Bob Colina (Vasco da Gama).

\section{Fim de Jogo}

Seja no mundo narrativo da crônica de José Lins do Rego, seja no personagem arquetípico de Nelson Rodrigues, o futebol literário presente nas crônicas da imprensa esportiva brasileira não é o futebol dos nossos gramados. É um futebol isomorfo a ele. Tal como no exemplo citado do filme Tron - O Legado, o futebol da crônica é um isomorfo do futebol real.
No entanto, é esse futebol da crônica que valoriza o jornalismo esportivo, bem como instaura a cultura do futebol presente nesse país. A mídia - antes dos craques e das equipes - é que faz o país amar o futebol. E ela o faz amar de uma maneira lírica, tal como saída de uma grandiosa fábula.

O mecanismo dos "mundos possíveis" de Umberto Eco nos possibilita entender um pouco mais de como podemos tornar o futebol lírico para poder amá-lo. É na crônica onde são criados heróis, vilões, paixões, ódios e, até mesmo, superstições. Sem a mídia com seus "outros mundos do futebol", não há futebol enquanto Beautiful Game. Ou, tal como disse Nelson Rodrigues,

A artejornalísticaconsiste empentear ou desgrenhar o acontecimento, e, de qualquer forma, negar a sua imagem autêntica e alvar.

Modelo de eficiência profissional foi aquele repórter que viu um incêndio (...). O jornalista espia o fogo e conclui que se tratava, na verdade, de um incêndio vagabundo, uma vergonha de incêndio. Qualquer mãe de família o apagaria com um humilhante regador de jardim. Volta o repórter para a redação e, lá, escreve uma página de jornal sobre o fracassado sinistro. E mais: - põe um canário inventado no meio das labaredas, um canário que morre cantando. No dia seguinte, a edição esgotou-se. A cidade inteira, de ponta a ponta, chorou a irreparável perda do bicho.

Vejam vocês a lição de vida e de jornalismo: - com duas mentiras, o repórter alcançara um admirável resultado poético e dramático (...). Sem passarinho, não há jornalismo possível (RODRIGUES, 1994, p. 12).

"Sem passarinho, não há jornalismo possível”. E o passarinho da crônica esportiva são os seus mundos possíveis. 


\section{Referências bibliográficas}

CARNAP, R. Meaning and Necessity. Chicago: UCP, 1947.

CARNAP, R. Logical Syntax of Language. Abingdon: Routledge, 2001.

ECO, U. Lector in Fabula. São Paulo: Perspectiva, 2008.

JEFFREY, R. The Logic of Decision. Chicago: UCP, 1983.

LANDINI, G. Russell. London: Routledge, 2011.

LEWIS, D. On the Plurality of Worlds. Malden: Blackwell, 2001.

PEARS, D. The False Prison - vol. 1. Oxford: OUP, 1987.

REGO, J. L. Flamengo é Puro Amor. Rio de Janeiro: José Olympio, 2002.

RODRIGUES, N. À Sombra das Chuteiras Imortais: Crônicas de Futebol. São Paulo: Cia das Letras, 1993.

RODRIGUES, N. A Pátria em Chuteiras: Novas Crônicas de Futebol. São Paulo: Cia das Letras, 1994.

SKYRMS, B. “Tractarian Nominalism”. Philosophical Studies. № 40. Dordrecht: D. Reidel, 1981

TORERO, J. R. \& PIMENTA, M. A. Futebol é bom pra cachorro. São Paulo: Panda, 2002.

WITTGENSTEIN, L. Investigações Filosóficas. São Paulo: Nova Cultural, 1999.

Este artigo e todo o conteúdo da Estudos em Jornalismo e Mídia estão

disponíveis em https://periodicos.ufsc.br/index.php/jornalismo

Estudos em Jornalismo e Mídia está sob a Licença Creative Commons 2.5 